coloproctology $2019 \cdot 41: 211$

https://doi.org/10.1007/s00053-019-0363-z

Published online: 30 April 2019

(c) Springer Medizin Verlag GmbH, ein Teil von Springer Nature 2019

\section{Comment to}

Andersson RE (2019) Less invasive pilonidal sinus surgical procedures.

coloproctology 41:117-120. https://doi.org/ 10.1007/s00053-019-0341-5

We read with interest the article "Less invasive pilonidal sinus surgical procedures" by R. E. Andersson, which reviews the current methods for minimally invasive treatment of pilonidal sinus disease (PSD). However, we feel that the article is not up to date with developments in this area, especially in the use of fibrin glue for PSD.

Fibrin glue for PSD was first described by us [4], as cited by Andersson, but he does not go on to mention subsequent reports of the wider use of fibrin glue as monotherapy, with healing seen in $96.9 \%$ in a larger cohort of 146 patients [5]. Neither does Andersson include further experience in the use of fibrin glue for PSD in children, a group who particularly benefit from the minimally invasive nature of the treatment, with a very short time away from school and excellent cosmesis [3]. Again, healing rates are high, with $94 \%$ achieving complete healing after glue alone.

We feel that the evidence base for the use of fibrin glue is increasing and this method has already proven to be both a safe and effective treatment in children and adults. Patient satisfaction is high and the procedure is quick and cheap to perform, especially when the cost of dressings, aftercare, and time off work or education are considered $[2,3,5]$. Fibrin

P. W. Thomas - P. J. J. Herrod - E. J. O. Hardy - T. S. Sian - J. E. M. Blackwell · H. BoydCarson ·. N. Lund

University of Nottingham, Royal Derby Hospital, Department of Colorectal Surgery, Medical Research Council-Arthritis Research UK Centre for Musculoskeletal Ageing Research, Derby, UK

\title{
Recent outcomes from the use of fibrin glue in pilonidal sinus disease
}

glue for PSD may be a treatment for PSD which finally meets the ideal criteria of Allen-Mersh: a low recurrence rate with high levels of success and minimal issue loss [1]. As such, we feel that an article updating your readers about less invasive pilonidal sinus surgical procedures should contain these facts to help them and their patients agree on the mode of treatment that is right for them.

\section{Corresponding address

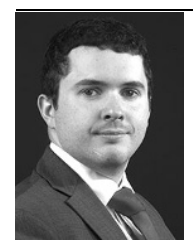 \\ P. J. J. Herrod \\ University of Nottingham, Royal Derby Hospital, Department of Colorectal Surgery, Medical Research Council-Arthritis Research UK Centre for Musculoskeletal Ageing Research DE22 3DT Derby, UK pherrod@nhs.net}

Conflict of interest P.W. Thomas, P.J.J. Herrod, E.J.O. Hardy, T.S. Sian, J.E.M. Blackwell, H. Boyd-Carson, and J.N. Lund declare that they have no competing interests.

\section{References}

1. Allen-Mersh TG (1990) Pilonidal sinus: Finding the right track for treatment. $\mathrm{Br} J$ Surg 77:123-132. https://doi.org/10.1002/bjs.1800770203

2. Elsey E, Lund JN (2013) Fibrin glue in the treatment for pilonidal sinus: high patient satisfaction and rapid return to normal activities. Tech Coloproctol 17:101-104. https://doi.org/10.1007/s10151012-0956-9

3. Hardy E, Herrod P, Sian T et al (2018) Fibrin glue oblitera on is safe, effective and minimally invasive as first line treatment for pilonidal sinus disease in children. J Pediatr Surg. https://doi.org/10.1016/J. JPEDSURG.2018.07.024
4. Lund JN, Leveson SH (2005) Fibrin Glue in the Treatment of Pilonidal Sinus: Results of a Pilot Study. Dis Colon Rectum 48:1094-1096. https://doi.org/10.1007/s10350-004-0905-4

5. Sian TS, Herrod PJJ, Blackwell JEM et al (2018) Fibrin glue is a quick and effective treatment for primary and recurrent pilonidal sinus disease. Tech Coloproctol 22:779-784. https://doi.org/10.1007/s10151-018-1864-4 